\title{
Feeding ecology, prey selection and growth performances of gold spot mullet, Liza parsia (Hamilton, 1822) in extensive brackish water farming system of Indian Sundarbans
}

\author{
Asish Mondal $^{1 *}$, Jitendra Kumar Sundaray ${ }^{2}$, Subhra Bikash Bhattacharyya ${ }^{1}$
}

, Prosenjit Pramanick ${ }^{1}$, Sufia Zaman ${ }^{1}$ and Abhijit Mitra ${ }^{3}$

${ }^{1}$ Department of Oceanography, Techno India University, Salt Lake campus, Kolkata, India

${ }^{2}$ ICAR-Central Institute of Freshwater Aquaculture, Kausalyaganga, Bhubaneswar-751 002, India

${ }^{3}$ Department of Marine Science, University of Calcutta, Ballygunge Circular Road, Kolkata-700019,

India

Received: July 12, 2017; Accepted: July 17, 2017; Published: July 20, 2017

*Corresponding author: Asish Mondal, M.Sc PhD holder cum Research Scholar, Department of Oceanography, Techno India University, Salt Lake campus, Kolkata, India, Tel:+91 9007806599; Fax: 9103210 255555; E-mail: asish177@gmail.com

\begin{abstract}
A study was aimed to focus on the feeding ecology with prey selection and growth performances of gold spot mullet (Liza parsia) in extensive polyfarming system. Three ponds (0.7-0.9 ha) were brought under observations which continued for 10 months (JanuaryNovember, 2015). Estuarine water containing wild fry of various species were allowed to enter in three impoundments. Commercial feed or fertilizer was not applied following common practice. Exchange of $20-30 \%$ water was carried out during lunar cycles. Water temperature and water depth were average $29.90 \mathrm{C}$ and $120 \mathrm{~cm}$. Order of dominance of prey groups in water was chlorophyceae, bacillariophyceae, myxophyceae, copepod and dinoflagelats. Tendency towards higher feeding intensity in terms of stomach fullness was observed as the fish grew. Order of dominance of prey groups in stomachs were myxophyceae, chlorophyceae, bacillariophyceae, dinoflagelatsand copepods while myxophyceae followed by bacillariophyceae was actively selected. Copepods were selected for first two months and negative selection of all zooplankton groups were noticed afterwards. L. parsia attained $58.94 \pm 2.02 \mathrm{~g}(15.2 \pm 0.19 \mathrm{~cm})$ at harvest with slope value of length-weight relationship $(b=3.028)$ and condition factor $(\mathrm{K}=1.26 \pm 0.11)$.Good growth and health condition in the present study can be attributed to the low production farming system with comparatively lower stocking density providing greater food and space for the growing fish.
\end{abstract}

Keywords: Liza parsia; feeding ecology; prey preference; growth; Extensive farming; Sundarbans.

\section{Introduction}

The gold spot mullet Liza parsia(Hamilton 1822), belonging to the family Mugilidae is a catadromousfish and widely distributed in the coastal waters of tropic, sub-tropic and temperate regions extending from $42^{\circ} \mathrm{N}$ to $42^{\circ} \mathrm{S}$ [1].With its good market price and consumer preference, abundant availability of seeds, non-carnivorous food habit, gold spot mullet is easily cultivable in shrimp growing areas and forms commercially important candidate for polyculture with shrimp and other mullets [2-5].Gold spot mullet, popularly known as 'parsia' in Indian subcontinent, can tolerate wide range of environmental fluctuation [6].

In India, L. parsia occurs in marine, shallow coastal water, shallow coastal lakes and brackish water estuaries and is reared in brackish water tide fed ponds in West Bengal $[7,8]$, in the estuaries and brackish water lakes of Kerala $[9,10]$ and in Lake Pulicat $[11,12]$. In West Bengal, the low-lying lands near estuaries and deltaic areas enclosed by embankments called "bheries" are used for traditional finfish cultivation mostly for mullets, especially during rains [13]. In bheries, large numbers of fish and shrimp seeds brought in through tidal water and partial stocking are reared for a period of 6-7 months [14] where gold spot mullet is an important component. Knowledge on species niche and growth potential in such extensive farming ecosystem is necessary for proper management and formulation of strategies for sustainable production improvement.

Studies on the food and feeding habit indicate the species niche in ecosystem, their food preference and food spectrum 
overlaps. Feeding behavior at the level of prey selection can have implications at the individual [15], population [16] and community levels [17]. But information on food spectrum and prey preferences of parsia in particular is scanty.

Growth performance of fish is one of the most important criteria for selection as a candidate species for farming. Available reports regarding growth of parsia is highly variable from farming systems. L. parsia fingerlings $(1.75 \mathrm{~g})$ were grown to 52.41 and $66.1 \mathrm{~g}$ in 18 months with Liza tade at ratios of 2:1 and $4: 1$ at overall stocking density of $25000 /$ ha in West Bengal coast [7]. Ali et al [2] reported growth of L. parsia fry (0.20g) up to $30.45 \mathrm{~g}$ at stocking density of 10000 nos/ha in 120 days of culture with Penaeus monodon at stocking density of 40000nos/ha in single crop system. He also reported that parsia fry were grown upto $47.68 \mathrm{~g}$ at similar initial size and stocking density in 225 days of rearing with P. monodon at stocking density of 20000nos/ha in double crop pattern. Much higher growth was reported by Biswas et al [8] where L. parsia fingerlings $(10.68 \pm 0.56)$ attained $54.02 \pm 2.11 \mathrm{~g}$ at stocking density of $2000 \mathrm{nos} / \mathrm{ha}$ in 180 days polyculture with Mugil cephalus (4500nos/ha), L. tade (1500nos/ ha) and P. monodon (20000nos/ha) in tide fed polyculture system. There is scarcity of information regarding growth of parsia in extensive farming system traditionally practiced in HooghlyMatla estuarine complex popularly known as Sundarbans.

The present study was aimed to assess feeding strategy along with prey preferences and growth performances of parsia reared in extensive polyculture system of Indian Sundarbans with a view towards optimum utilization of this high value species in improved polyculture utilizing all the potential food of the water bodies without much competition.

\section{Materials and Methods}

Gopalnagar Dakshin village coordinating 21.802$21.807^{\circ} \mathrm{N}, 88.296-88.298^{\circ} \mathrm{E}$ of Pathapratima Block, South 24 Parganas, West Bengal, India situated at the bank of HataniaDoania River was selected. Three ponds (0.7-0.9 ha) were brought under observations which continued for 10 months (JanuaryNovember, 2015). Initially, the ponds were dewatered and sun dried. Liming was done over the dried pond bottom using Lime Stone Powder (LSP) @500 kg/ha during first week of January. Ponds were filled with high tidal saline water (18.5ppt) up to a depth of $120 \mathrm{~cm}$ during second week of January after filtration through traditional bamboo screen. Small fry can enter through traditional bamboo screen during water exchanges but exit of bigger fishes is restricted. As seeds of L. parsia remain available in north-east coast of India during the month of January-March $[2,4,18]$, entry of gold spot mullet fry along with other species was anticipated. Following traditional practice, no fertilizer or supplementary feed was used and fishes grew depending on natural food. Natural food was brought in through exchange of $20-30 \%$ water during lunar cycles. Pond water and fish samples were collected monthly mid-February onwards from three ponds and analyzed.

The pond water samples were collected between 09:00 and 10:00 hours. Water quality parameters viz. temperature, salinity,
$\mathrm{pH}$, dissolved oxygen (DO), nitrite-nitrogen (NO2-N), nitratenitrogen (NO3-N), ammonia-nitrogen (NH3-N) and phosphatephosphorus (PO4-P) were analyzed following Standard Methods [19]. Water salinity was measured using a refractometer (ATAGO, Japan). Plankton sample collection was done using bolting silk plankton net (mesh size $64 \mu \mathrm{m}$ ) by filtering $100 \mathrm{~L}$ of pond water. Concentrated plankton samples were preserved in $5 \%$ buffered formalin. Plankton constituents were identified and counted following direct census method[18, 20].Planktonic constituents of pond water were classified as chlorophyceae (Green algae), bacillariophyceae (Diatoms), myxophyceae (Blue green algae), copepods, dinoflagelats, macrophyte parts and fish and shrimp larvae.

Stomachs of ten fishes from each impoundment every month were removed intact and feeding intensity based on fullness of stomachs was recorded by visual estimation and classified as gorged, full, $3 / 4$ full, $1 / 2$ full, $1 / 4$ full, Little and empty [21]. Stomach contents were preserved in fixed volume of $5 \%$ buffered formalin. Planktonic constituents of fish stomachs were identified and counted following direct census method $[18,20]$ using SedgwickRafter counting cell and classified in same way as pond water. Additionally, organic matter and sand and mud particles were evaluated as major stomach constituents. Numeric percentages of each group were calculated.

Ivlev's Electivity Index [22] was used to determine prey preferences. Percentage compositions of food items in stomach were compared with that of studied pond water using the following formula:

$$
E=\frac{r-p}{r+p}
$$

Where, $r=$ percentage of dietary item in ingested food, $p=$ percentage of prey in the environment.

Gravimetric data like total length (TL, $\mathrm{cm}$ ) was recorded with a slide caliper, while body weight $(\mathrm{W}, \mathrm{g})$ was measured using a digital electronic balance prior to dissection for stomach analysis. Ten fishes from each three ponds were collected monthly midFebruary onwards i.e. 30 fish in a month and total 300 fish were analyzed throughout the study period. The following formula was used to determine daily weight gain (DWG):

$$
D W G=\frac{W_{f}-W_{i}}{t}
$$

Where $\mathrm{W}_{\mathrm{f}}$ and $\mathrm{W}_{\mathrm{i}}$ are the average final and initial weight in time t.

Specific growth rate (SGR) was determined using the conventional equation:

$$
S G R=\frac{\ln w_{f}-\ln w_{i}}{t} \times 100
$$


Where $\mathrm{W}_{f}$ and $\mathrm{W}_{i}$ are the average final and initial weight in time t.

Length-weight relationship was determined using the following mathematical relationship proposed by Pauly [23]:

$$
W=a \cdot T L^{b}
$$

Where $W$ is fish weight (g), TL is total length (cm), ' $a$ ' is the proportionality constant and ' $b$ ' is the isometric exponent. The parameters $a$ and $b$ were estimated by non-linear regression analysis.

Fulton's condition equation was used to find out the condition factor [24]:

$$
K=\frac{\bar{w}}{\overline{(T L)^{3}}} \times 10^{2}
$$

Where $\mathrm{K}$ is the condition factor, $\mathrm{w}^{-}$is the average weight $(\mathrm{g})$ and (TL) is the average total length $(\mathrm{cm})$

Differences in growth parameters of fish among ponds were determined by analysis of variance with the General Linear Model procedure using SPSS for Windows v.17.0 program me (SPSS Inc Chicago IL USA). Duncan's Multiple Range Test [25] was used for comparison of data. All data are expressed as mean \pm standard error (S.E.).

\section{Results}

Physico-chemical parameters in three studied ponds are presented in table 1 . Highest temperature was recorded during the month of April (34.2oC) and lowest during November (19.5oC). Dissolved oxygen (DO) varied from $5.80 \pm 0.42$ to $9.10 \pm 0.50 \mathrm{mg} / \mathrm{L}$. Surface water $\mathrm{pH}$ varied between $7.92 \pm 0.3$ to $8.72 \pm 0.4$ and remained almost steady throughout the study period. Dissolved oxygen and $\mathrm{pH}$ were almost similar in pond 1 and pond 2 but those were significantly $(\mathrm{p}<0.05)$ lower in pond 3.Salinity fluctuation showed wide variations in three ponds with maximum (18.8 $\pm 4.8 \mathrm{ppt}$ ) during May (summer) and minimum (3.4 $\pm 1.4 \mathrm{ppt}$ ) during August (monsoon). Concentration of nitrogenous metabolites like Nitrite-nitrogen (NO2-N) and total ammonia nitrogen (NH3-N) were recorded between $9.33 \pm 2.5-24.47 \pm 5.8$ and $21.83 \pm 5.7-44.08 \pm 5.4 \mu \mathrm{g} / \mathrm{L}$, respectively. Concentration of nutrients like nitrate-nitrogen (NO3-N) and phosphate-phosphorous (P04-P) ranged between 69.62 \pm 6.9 $111.04 \pm 9.8$ and $21.58 \pm 5.8-43.27 \pm 6.5 \mu \mathrm{g} / \mathrm{L}$, respectively. Nitratenitrogen and phosphate-phosphorous concentration showed no significant difference $(\mathrm{p}<0.05)$ among ponds. Phytoplankton and zooplankton concentration was significantly higher $(\mathrm{p}<0.05)$ in pond 1 and lower in pond 3 .

Percentage occurrences of planktonic and other suspended food components in pond water are presented in figure 1.The most abundant phytoplankton groups in three ponds according to the order of dominance were chlorophyceae, bacillariophyceae and bymxophyceae. The most abundant genera found under chlorophyceae were Enteromorpha, Ulothrix, Pediastrum, Chlorella and Tetraedron. Numeric percentage of chlorophyceae ranged between 21.03 and $37.41 \%(29.59 \pm 3.01 \%)$ during May and April respectively. Among bacillariophyceae, Navicula, Nitzschia, Cyclotella, Basilaria, Diatoma and Melosira were found to be the most abundant genera. Numeric percentage of bacillariophyceae ranged between 8.96 and $30.99 \%(22.59 \pm 4.34 \%)$ during July and September, respectively. Anabaena, Nostoc, Spirulina and Oscillatoria was the most dominant genera undermyxophyceae. The percentage composition of myxophyceae varied between 15.06 and $25.92 \%(21.38 \pm 2.33 \%)$ throughout the study period. Among zooplankton groups, copepods and dinoflagelats were most dominant while rotifersandcladocera were less abundant. Percentage composition of copepoda ranged between 2.04 to 24.88\% and most common Copepod genera was Calanus. Most abundant dinoflagelats genera were Ceratium and Peridinium. Percentage composition of dinoflagelats were recorded minimum

\begin{tabular}{|c|c|c|c|}
\hline Water parameters & Pond 1 & Pond 2 & Pond 3 \\
\hline Temperature $\left({ }^{\circ} \mathrm{C}\right)$ & $29.9 \pm 1.7$ & $29.9 \pm 1.7$ & $29.7 \pm 1.9$ \\
\hline $\mathrm{pH}$ & $8.04 \pm 0.23^{\mathrm{a}}$ & $7.96 \pm 0.25^{\mathrm{a}}$ & $7.78 \pm 0.31^{\mathrm{b}}$ \\
\hline $\mathrm{DO}\left(\mathrm{mg} \mathrm{L}^{-1}\right)$ & $6.06 \pm 0.42^{\mathrm{a}}$ & $5.99 \pm 0.52^{\mathrm{a}}$ & $5.69 \pm 0.52^{\mathrm{b}}$ \\
\hline Salinity (ppt) & $12.87 \pm 5.34$ & $12.74 \pm 5.32$ & $12.89 \pm 5.19$ \\
\hline $\mathrm{NO}_{2}-\mathrm{N}\left(\mu \mathrm{g} \mathrm{L}^{-1}\right)$ & $16.35 \pm 5.83$ & $15.91 \pm 5.62$ & $16.11 \pm 6.63$ \\
\hline $\mathrm{NO}_{3}-\mathrm{N}\left(\mu \mathrm{g} \mathrm{L}^{-1}\right)$ & $93.12 \pm 15.41$ & $92.66 \pm 11.14$ & $92.97 \pm 8.94$ \\
\hline $\mathrm{NH}_{4}-\mathrm{N}\left(\mu \mathrm{g} \mathrm{L}{ }^{-1}\right)$ & $30.96 \pm 5.61^{\mathrm{b}}$ & $31.19 \pm 7.91^{\mathrm{b}}$ & $34.89 \pm 6.27^{\mathrm{a}}$ \\
\hline $\mathrm{PO}_{4}-\mathrm{P}\left(\mu \mathrm{g} \mathrm{L}^{-1}\right)$ & $32.07 \pm 13.43$ & $31.91 \pm 11.98$ & $31.89 \pm 12.74$ \\
\hline Phytoplankton(numbers $/ \mathrm{L}^{-1} \times 10^{3}$ ) & $15.38 \pm 1.62^{\mathrm{a}}$ & $15.12 \pm 1.94^{\mathrm{b}}$ & $14.95 \pm 1.73^{\mathrm{c}}$ \\
\hline Zooplankton (numbers $/ \mathrm{L}^{-1} \times 10^{3}$ ) & $3.05 \pm 0.25^{\mathrm{a}}$ & $2.91 \pm 0.23^{\mathrm{b}}$ & $2.83 \pm 0.17^{\mathrm{c}}$ \\
\hline \multicolumn{4}{|c|}{$\begin{array}{l}\text { Means bearing different superscripts indicate statistically significant differences in a } \\
\text { row }(p<0.05) \text {; Values are expressed as mean } \pm \text { SE }(n=10 \text { for each impoundments every } \\
\text { month) }\end{array}$} \\
\hline
\end{tabular}
during June (4.21\%) and maximum during November (20.00\%).

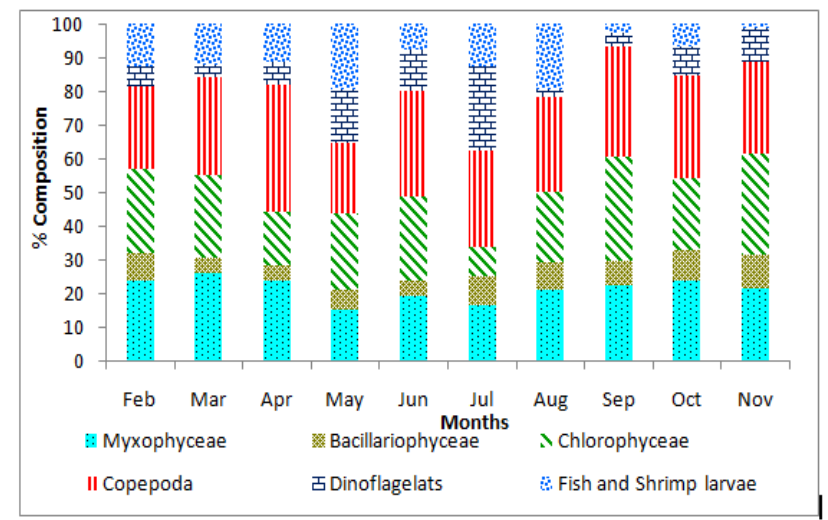

Figure 1: Percentage occurrences of suspended food materials in ambient water of extensive farming impoundments selected for gold spot mullet (Liza parsia) feeding ecology study 
Feeding intensity of gold spot mullet in terms of stomach fullness is presented in table2. Overall, only $6.6 \%$ fishes were found with empty stomach considering the whole study period. Most of the fish stomachs were observed with $1 / 4$ full $(21.88 \%)$, $1 / 2$ full $(18.40 \%)$ and $3 / 4$ full $(17.99 \%)$ stomachs indicating moderate feeding. Highest gorged stomachs was recorded during
June $(22.2 \%)$ and lowest during October (1\%) whereas highest $(14.8 \%)$ and lowest $(0 \%)$ empty stomachs were found during November and August, respectively. A tendency towards higher feeding intensity was observed as the fishes grew as gorged, full and $3 / 4$ full stomachs were gradually increased and $1 / 2$ full, little food and empty stomachs gradually decreased.

Table 2: Feeding intensity in terms of stomach fullness in gold spot mullet (Liza parsia) grew in extensive brackish water ponds

\begin{tabular}{|c|c|c|c|c|c|c|c|}
\hline Months & Gorged & Full & $3 / 4$ Full & $1 / 2$ Full & $1 / 4$ Full & Little & Empty \\
\hline Feb & 8 & 15 & 19 & 13 & 27 & 4.5 & 13.5 \\
\hline Mar & 5.5 & 20 & 20 & 20 & 19 & 5.5 & 10 \\
\hline Apr & 9.1 & 10.5 & 31 & 15.6 & 16.8 & 10.5 & 6.5 \\
\hline May & 14 & 15.2 & 10 & 20.5 & 23.3 & 16 & 1 \\
\hline Jun & 22.2 & 16.7 & 12.1 & 16.7 & 21.2 & 8.1 & 3 \\
\hline Jul & 6.7 & 10 & 13 & 16.6 & 26 & 25.2 & 2.5 \\
\hline Aug & 12.6 & 13.3 & 20 & 26.5 & 27.6 & 0 & 0 \\
\hline Sep & 21.2 & 10.7 & 24 & 11.8 & 11.3 & 19 & 2 \\
\hline Oct & 1 & 10 & 20.3 & 20 & 20 & 16 & 12.7 \\
\hline Nov & 5 & 13.2 & 10.5 & 23.3 & 26.6 & 6.6 & 14.8 \\
\hline
\end{tabular}

Percentage occurrences of food materials observed in the gold spot mullet stomachs are presented in figure 2 and 3 .The dominant phytoplankton groups in the fish stomach according to the order of dominance were myxophyceae (19.37 in November -39.86\% in June; $29.33 \pm 1.82 \%$ ), chlorophyceae(13.04in July-21.54 in September;17.30 $\pm 1.05 \%$ ) and bacillariophyceae (4.45in April13.61\%in November; $9.02 \pm 1.05 \%$ ). Most abundant zooplankton groups were dinoflagelats (1.14 in September -6.37\% in October; $2.87 \pm 0.55 \%)$ and copepod ( 0.12 in April $-4.89 \%$ in February; $2.23 \pm 0.62 \%)$.Among non-planktonic contents, higher plant materials (9.85 in August-19.03\% in November; 13.38 \pm 1.01 ), fish and shrimp parts $(0.12 \%$ in April-3.19\% in May; $1.00 \pm 0.29 \%)$, debris-sand-mud (19.00in February-32.00\% in August; $24.87 \pm 1.34 \%$ ) were also present.

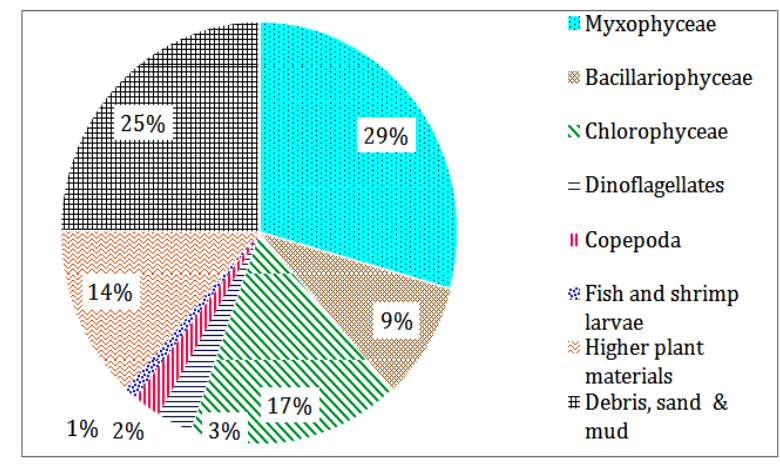

Figure 2: Average percentage occurrences of food materials in gold spot mullet (Liza parsia) stomachs grew in extensive farming system.



Figure 3: Monthly percentage occurrences of food materials in gold spot mullet (Liza parsia) stomachs grew in extensive farming system.

Month wise electivity index (E)of different food categories are presented in figure 4.Gold spot mullet showed highest preference towards myxophyceae with significant positive E value of$0.37 \pm 0.08$ ranging between -0.25 and- 0.53 during October and May, respectively. Bacillariophyceae was found to be second most preferred group with significant positive E of $-34 \pm 0.06$ which varied between- 0.22 during May and - 0.49 during September. E for chlorophyceae ranged between - 0.02 to -0.40 during November and July, respectively indicating third most preferred ( $E=-0.12 \pm 0.08$ ) prey group. Copepods showed positive value of $E$ during early months which gradually decreased as the fish grew and varied between- 0.17 to -0.92 and mean value $(-0.46 \pm 0.30)$ indicated negative selection. E for fish and shrimp parts and dinoflagelats ranged between -0.23 to- $0.97(-0.68 \pm 0.16)$ and 
-0.51 to $-0.90(-0.73 \pm 0.09)$ respectively indicating strong negative selection.

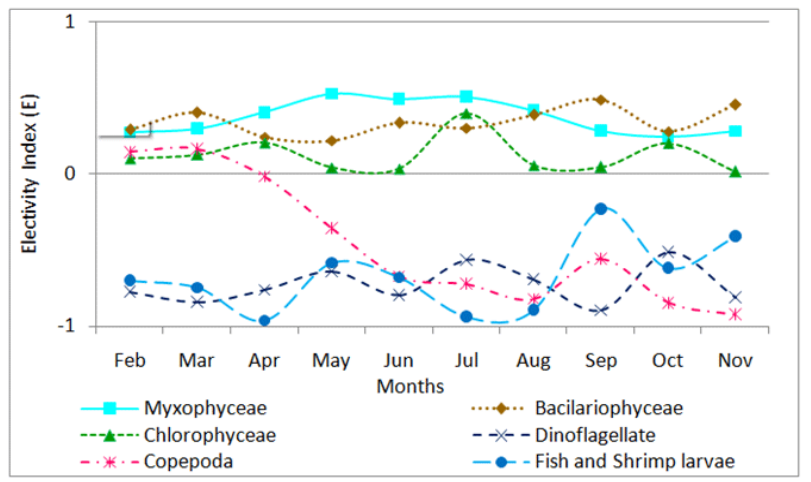

Figure 4: Electivity index indicating prey preference of gold spot mullet (Liza parsia) grew in extensive farming system

Gold spot mullet fry entered the impoundments during January grew to $3.4 \pm 1.3 \mathrm{~g}(6.5 \pm 0.21 \mathrm{~cm})$ during February as revealed from first sampling. Those who attained $58.94 \pm 2.02 \mathrm{~g}(15.2 \pm 0.19 \mathrm{~cm})$ at harvest during mid-November (figure 5) registering daily weight gain (DWG) of $0.21 \pm 0.04 \mathrm{~g}$ day-1 and specific growth rate (SGR) of $1.06 \pm 0.20 \%$ day- 1 . Fulton's condition factor $(\mathrm{K})$ estimated was $1.26 \pm 0.11$ considering the whole study period (figure 6). LengthWeight Relationship (LWR) showed curvilinear growth pattern with exponent value of 3.028 indicating positive allow metric growth (figure 7).

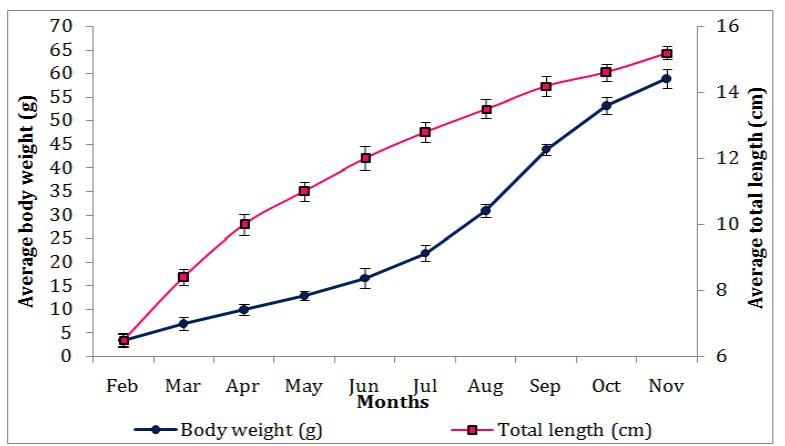

Figure 5: Growth of gold spot mullet (Liza parsia) in extensive farming system (values are expressed as mean $\pm \mathrm{SE}$ of three studied ponds)

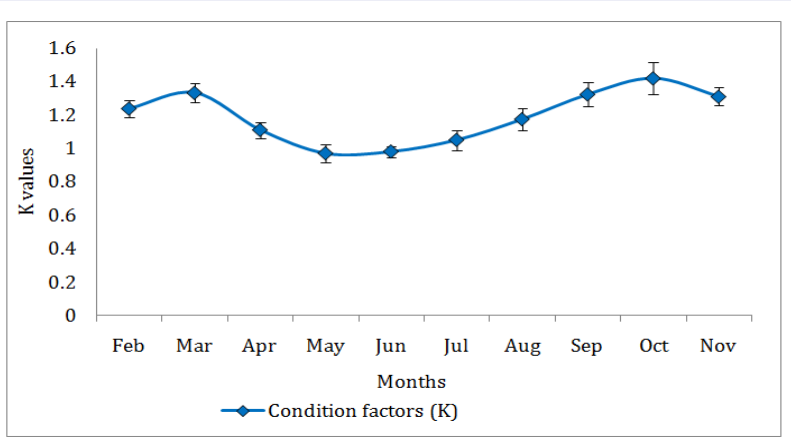

Figure 6: Condition factors (K) of gold spot mullet (Liza parsia) reared in extensive farming system

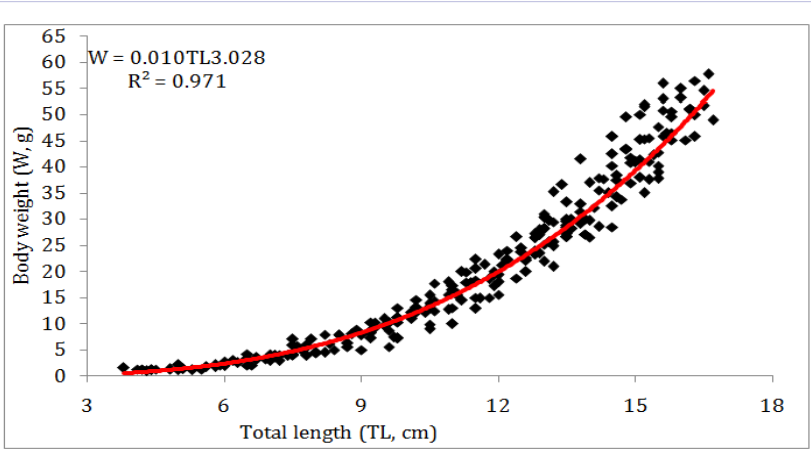

Figure 7: Length--weight relationship of gold spot mullet (Liza parsia) grew in extensive farming system

\section{Discussion}

Water quality parameters in the studied extensive ponds were within the optimum ranges for brackish water aquaculture [2, 26 and27]. Concentrations of toxic metabolites like nitritenitrogen (NO2-N)and ammonia-nitrogen (NH4-N) remained lower than the critical level and concentrations of nutrients like nitrate-nitrogen (NO3-N) and phosphate-phosphorous (PO4-P) was much lower than fertilized ponds reported from Sundarbans $[4,28]$ and corroborated with those reported earlier by Mondal et al [29] from the same location. Lower nutrient concentrations in the studied extensive system may be attributed to complete dependence on natural productivity without any additional input.

Order of dominance of the planktonic groups in the ambient water in the present study corroborated with that reported from the Hooghly estuary and shrimp farming ponds in Sundarbans [28].Extensive farming can be considered as representative of the natural environment as it depends only on the natural productivity. Existence of planktonic community structure resembling the natural environment in such farming system can be expected.

Gold spot mullet in tide fed extensive farming systems coexists with other herbivorous and carnivorous fishes. Carnivores like Lates calcarifer, Therapon jarbua, Eleutheronema tetradactylum, Glossogobius giuris and many more gains entry in extensive system during tidal water exchange [8]. As smaller fishes are more vulnerable, they would rather feed more cautiously than their bigger counterpart due to the fear of potential predators resulting in lower feeding frequency in smaller fishes [30]. Larger fish may require more food to obtain the necessary energy for reproductive activity than smaller ones require for growth. In larger fish, a wider mouth opening helps to ingest relatively large quantity food items at a time compared to smaller ones [31].

Quantitative and qualitative changes in fish food during the life span are useful tools to define the diet of a particular fish species [32, 33]. Planktonic algae were reported to be the dominant food item of L. parsia and planktonic groups according to the order dominance was chlorophyceae, bacillariophyceae and myxophyceae [3] in open environment. The percentage occurrence of filamentous algae (53\%) and diatoms (54.1\%) was more or less equal through considerable monthly variations were seen among the two food items [34]. In the present study, 
similar order of dominance of planktonic groups was observed in extensive farming system but percentage occurrence of different planktonic groups widely differed from the previous reports.

Fish food preferences were determined through electivity index (E) to throw some light on the preferred food of gold spot mullet in extensive farming system. Ribeiro and Nuňer [35] suggested that changes of feeding habits of a fish species are a function of the interactions among several environmental factors that will influence the selection of food item. In the present study, gold spot mullet showed highest preference towards myxophyceae followed by bacillariophyceae, chlorophyceae, copepod, fish and shrimp parts and dinoflagelets. According to Ivlev's equation [36], $\mathrm{E}$ varies from -1 to +1 , where 0 to +1 stands for positive selection, while values between -1 to 0 indicates negative selection of that prey item while true positive or negative prey selection can be interpreted only at values $>0.3$ or $<-0.3$ respectively [37]. In the present study, L. parsia truly selected myxophyceae though ranking 3rdin the order of dominance in the ambient water making it the prime food material in the stomach. Although being 2nddominant planktonic constituent in water and third in stomach, bacillariophyceae was observed to be the 2nd most preferred truly selected prey group. In spite of being dominant prey group in pond water and 2 nd in the order of dominance in the stomach content, chlorophyceae ranked 3rd in order of preference. Chlorophyceae was not truly selected and probably swallowed mechanically during food intake as those were most abundant in water. Gold spot mullet juveniles positively selected copepoda during the initial months of rearing but true negative selection was observed during third month onwards. Fish and shrimp parts and dinoflagelets were not at all selected by L. parsia. Order of preference of phytoplanktonic food by $L$. parsia as myxophyceae $>$ bacillariophyceae $>$ chlorophyceae is different from coexisting species like Mugil cephalus $L$ bacillario phyceae>myxophyceae>chlorophyceae [29] and Liza tade as ch lorophyceae>myxophyceae>bacillariophyceae [38] in the same environment suggests feeding strategy of mullets to reduce inter specific competition within the same tropic level.

Growth of gold spot mullet in the present study $(58.94 \pm 0.02$ g, $15.2 \pm 0.19 \mathrm{~cm}$ ) was much higher than $47.68 \mathrm{~g}$ in 225 days at stocking density of 10000 fish ha-1 as reported by Ali et al [2] and $54.02 \pm 2.11 \mathrm{~g}$ at stocking density of 2000 no's/ ha in 180 days polyculture with M. cephalus (4500 no's/ ha), L. tade (1500 no's/ ha) and P. monodon (20000 no's/ ha) in fed polyculture system [8]. L. parsia in the present study showed better survival and DWG compared to those reported by Bhowmik [7]. Much lower growth $(27.03 \pm 2.662 \mathrm{~g}, 12.97 \mathrm{~cm})$ compared to the present study was reported from Bangladesh in shrimp- mullet polyculture [39]. Slope value of length-weight relationship in the present study $(b=3.028)$ was much higher than those reported from Southern India as 2.796 and 2.988 for male and female respectively. Better growth and health condition observed in the present study can be attributed to the low production farming system with comparatively lower stocking density providing greater food and space for the growing fishes.

\section{Acknowledgements}

The authors are extremely grateful to the authorities of Techno India University, Salt Lake, Kolkata for providing laboratory facilities. The authors are deeply thankful to the faculty members, Professors, supporting staffs and colleagues for their continuous encouragement, priceless research comments, valuable guidance and important suggestions

\section{Conflict of Interest Statement}

The authors declare that the research was conducted in the absence of any commercial or financial relationships that could be construed as a potential conflict of interest.

\section{References}

1. Talwar PK, Jhingram AG. Inland Fisheries of India and Adjacent Countries, Vol 2. TYK Prokason Dhaka.1991:561.

2. Ali MS, Shofiquzzoha AFM, Ahmed SU. Observation on the production performance of Penaeus monodon with Liza parsia under different cropping system. Brackish water station Bangladesh fisheries research institute Paikgaclza Khulna 9280. Bangladesh Fish. Res. 2000;4(2):141-145.

3. Joadder AR, Hossain MD. Convenient Pattern of food and Feeding Habit of Liza Parsia (Hamilton) (Mugiliformes: Mugilidae). Journal of Fisheries International. 2008;3(3):61-64.

4. Biswas G, De D, Thirunavukkarasu AR, Natarajan M, Sundaray JK, Kailasam M, et al. Effects of stocking density, feeding, fertilization and combined fertilization-feeding on the performances of striped grey mullet (Mugil cephalus L.) fingerlings in brackishwater pond rearing systems. Aquaculture. 2012;338(341):284-292.

5. Bir J, Islam MR, Shah MS, Islam SS, Sabbir W. Fecundity, Gonado-Somatic Index (GSI), Conditioning Factors, Food and Feeding Habit and Length- Weight Relationship of Gold Spot Mullet, Liza parsia. Khulna University studies. 2013;11,12(1\&2):67-75.

6. Riede K. Global register of migratory species: from global to regional scales: Final Report of the R\&D-Project 80805 081. Federal Agency for Nature Conservation. 2004:329.

7. Bhowmik ML, Chakraborti RK, Das NK, Mondal SK. On the mixed culture of Liza tade(Forskal) and Liza parsia(Ham) in brackishwater with reference to pond ecology. Impacts of Environment on Animals and Aquaculture (Eds G K Manna and B B Jana). 1990:187-193.

8. Biswas G, Ananda Raja R, De D, Sundaray JK, Ghoshal TK, Annand S, et al. Evaluation of productions and economic returns from two brackishwater polyculture systems in tide-fed ponds. Journal of Applied Ichthyology. 2012;28(1):116-122.

9. Kurup BM, Samuel CT. Fish and fishery resources of the Vembanan lake ProSymp Harvest and post-Harvest. Technology of Fisheries.1985:7782.

10. Renjini PK, BijoyNandan S. Length-Weight relationship, condition factor and morphometry of gold spot mullet Liza parsia (Hamilton, 1822) from Cochin estuary. Indian Journal of Geo-marine Science. 2011;40(4):567-571.

11. Sarojini KK. Biology and fisheries of the grey mullets of Bengal I. biology of Mugil parsia Hamilton with notes on its fishery in Bengal. Indian Journal of Fisheries. 1957;4(1):160-207. 
12. Ghosh AN, Das PR, LK Das. Experimental observations on the food requirement of fry of Mugil parsia (Hamilton) In Coastal Aquaculture in the Indo-Pacific Region Ed Pillay TVR. 1974:429-37.

13. Pillai VN, Menon NG. A review of marine finfish culture experiments in India. Marine Fisheries Research Institute (ICAR). 2000.

14. Biswas G, Thirunavukkarasu AR, Sundaray JK, Kailasam M. Optimization of feeding frequency of Asian seabass (Lates calcarifer) fry reared in net cages under brackishwater environment. Aquaculture. 2010;305(1-4):26-31.

15. Fraser D, Huntingford FA, Adams CE. Foraging specialisms, prey size and life-history patterns: a test of predictions using sympatric polymorphic Arctic charr (Salvelinus alpinus). Ecology of Freshwater Fish. 2007;17(1):1-9.

16. Herwig BR and Zimmer KD. Population ecology and prey consumption by fathead minnows in prairie wetlands: importance of detritus and larval fish. Ecology of Freshwater Fish. 2007;16(3):282-294.

17. Schleuter D, Eckmann R. Generalist versus specialist: the performances of perch and ruffe in a lake of low productivity. Ecology of Freshwater Fish. 2007;17(1):86-99.

18.Jhingran VG, Natarajan AV, Banerjee SM, David A. Methodology on reservoir fisheries investigation in India. Central Inland Fisheries Research Institute Barrackpore, India Bulletin No 12. 1969:109.

19.APHA. Standard Methods for the Examination of Water and Wastewater, 20th ed. American Public Health Association Washington DC USA. 1998.

20. Prescott GW. Algae of the Western Great Lakes Area. WMC Brown Company Publishers Dubuque IA USA. 1961:990.

21. Abdelghany AE. Food and feeding habits of Nile tilapia from the Nile River at Cairo Egypt, L Reintertsen, A Dhale, C Jorgensen, R Twinnereim (Eds). Fish Farm Technology AA Balkema Rotterdam The Neatherland. 1993:447-453.

22. Jacobs J. Quantitative measurement of food selection: A modification of the Forage Ratio and the Ivlev's Electivity Index. Oecologia. 1974;14(4):413-417. doi:10.1007/BF00384581

23. Pauly D. Fish population dynamics in tropical water a manual for the use with programmable calculators. ICLARM Stud. Rev. 1984: 325.

24. Chow S, Sandifer PA. Differences in growth, morphometric traits and male sexual maturity among Pacific white shrimp Peneaus vannamei from different commercial hatcheries. Aquaculture. 1991;92:165-178.

25. Duncan DB. Multiple range and multiple F-tests. Biometrics. 1955;11(1):1-42.

26. Bhowmik ML, Chakraborti RK, Mandal SK, Ghosh PK. Growth of Penaeus monodon(Fab) under variable stocking densities. Environ Ecol.1992;10:825-828.
27. Chakraborti RK, Sundaray JK and Ghoshal TK. Production of Penaeus monodon in the tide fed ponds of Sunderbans. Indian Journal of Fisheries. 2002;49:419-426.

28. Saha SB, Bhattacharyya SB, Mitra A, Choudhury A. Quality of shrimp culture farm effluents and its impact on the receiving environment. Bangladesh Journal of Zoology. 2001;29:139-149.

29. Mondal A, Chakravortty D, Mandal S, Bhattacharyya SB, Mitra A. Feeding ecology and prey preference of grey mullet, Mugil Cephalus (Linnaeus,1758) in extensive brackish water farming system. Journal of Marine Science: Research \& Development. 2015; 178(6). doi:10.4172/2155-9910.1000178

30. Akpan AW, Isangedighi IA. Aspects of the Feeding Ecology of three Species of Pseudotolithus (Sciaenidae) in the inshore waters of Southeastern Nigeria, East of the Niger Delta, Nigeria. Journal of Aquatic Sciences. 2004;19(2):51-58.

31. Isangedighi IA, Uudo PJ, Ekpo IE. Diet composition of Mugil cephalus (Pisces: mugilidae) in the Cross River estuary, Niger delta, Nigeria. Nigerian Journal of Agriculture, Food \& Environment. 2009;5(2-4):1015.

32. Shamsi M1K. Environmental biology of plankton and macro fauna of perennial and sewage-fed water body. PhD thesis Aligarh Muslim University India. 1984.

33. AL-Ake1 AS, AL-Kahem HF, Shamsi MJK, Ahmed Z. Selection of food in various size groups of Nile Ti1apia Oreochromis niloticus (L) in Wadi Haneefah stream, Saudi Arabia. Pakistan J. Zool. 1996;28(4):271-275.

34. Babu KS, Neelkantan B. Biology of Liza parsia in the Kali Estuary, Karwar. Mahasagar-Bulletin of the National Institute of Oceanography. 1983;16(3):381-389.

35. Ribeiro DFO, Nuňer APO. Feed preferences of Salminus brasiliensis (Pisces Characidae) larvae in fish ponds. Aquaculture. 2008; 274(1):65 $-71$.

36. Ivlev VS. Experimental ecology of the feeding of fisheries. Yale University Press New Haven CT USA. 1961:322.

37. Lazzaro X. A review of planktivorous fishes: their evolution feeding behaviors, selectivities, and impacts. Hydrobiologia. 1987;146: 97-167.

38. Mondal A, Bhattacharyya SB, Mandal S, Purkait S, Chakravartty D, Mitra A. Growth performances, feeding ecology and prey preferences of tade mullet, Liza tade (Forsskål, 1775) in extensive brackishwater farming system. International Journal of Fisheries and Aquatic Studies. 2016;4(3):436-443.

39. Shofiquzzoha AFM, Islam ML, Ahmed SU. Optimization of stocking rates of shrimp (P. monodon) with brackishwater finfish in a polyculture system. Journal of Biological Sciences. 2001;1(8):694-697. 